Quebec Cooperative Study of Friedreich's Ataxia

\title{
Cerebellar Ataxia Produced by 3-Acetyl Pyridine in Rat
}

\author{
R. F. BUTTERWORTH, E. HAMEL, F. LANDREVILLE AND A. BARBEAU
}

SUMMARY: A single intraperitoneal injection of 3-acetyl pyridine produces, within 24 hours of administration, signs of cerebellar ataxia and damage to the medulla oblongata and to the climbing fibers of the cerebellum. These changes are accompanied by changes in the concentration of certain amino acids in the appropriate areas. Glutamic acid is decreased in cerebellum, medulla, cortex, striatum, hippocampas, retina and olfactory bulbs, while taurine is specifically decreased in the cerebellum and medulla oblongata and aspartic acid in the retina. The concentrations of $G A B A$ and glycine are not modified in any of the areas studied. Glutamine is generally increased in concentration in areas of cell damage.

RESUME: Une injection intrapéritonéale unique de 3-acetyl pyridine produit, en dedans de 24 heures du moment de l'administration, des signes d'ataxie cérébelleuse accompagnés de lésions pathologiques au tronc cérébral et aux fibres grimpantes du cervelet. Ces changements sont associés à des modifications dans la concentration de certains acides aminés aux régions appropriées. Ainsi l'acide glutamique est déficitaire au cervelet, tronc cérébral, cortex, striatum, hippocampe, rétine et bulbes olfactifs alors que la taurine est spécifiquement en basse concentration dans le cervelet et le tronc cérébral et que l'acide aspartique est diminué dans la rétine. Il n'y a aucune modification des concentrations régionales de GABA ou de glycine. Enfin la glutamine est généralement en concentration élevée dans les zones où il y a lésions cellulaires.

From: The Department of Neurobiology, Clinical Research Institute of Montreal.

Reprint requests for the complete supplement on Friedreich's ataxia (Phase two, Part One) to: Dr. André Barbeau. Clinical Research Institute of Montreal, 110 Pine Avenue West, Montreal, Quebec, Canada H2W 1R7.

\section{INTRODUCTION}

A progressive familial form of cerebellar ataxia involving degeneration of the olives and cerebellum, (olivocerebellar atrophy, OCA) was first described by Holmes in 1907. Pathological changes in the condition include atrophy of the inferior olives and olivocerebellar connections. Isolated cases involving degeneration of the posterior columns and the spinocerebellar tracts or corticospinal tracts provide a connecting link between these cases and those of Friedreich's ataxia.

In experimental animals, a single intraperitoneal injection of 3-acetyl pyridine produces, within 24 hours of administration, signs of cerebellar ataxia and pathological changes in comparable areas of brain to those affected in OCA (Desclin \& Escubi, 1974). We have investigated this model of experimental ataxia with reference to changes in levels of 6 key cerebral amino acids, 5 of which have been implicated as possible neurotransmitters in the central nervous system.

\section{MATERIALS AND METHODS}

Adult male Sprague-Dawley rats weighing 275-300 g were injected intraperitoneally with a solution of 3-acetyl pyridine in saline at a dosage of $75 \mathrm{mg}$ per $\mathrm{kg}$. Control animals received equivalent volumes of saline. Three days following treatment, the animals were sacrificed, brains quickly removed and dissected on ice into the following regions: cerebral cortex, hippocampus, striatum, hypothalamus, midbrain, cerebellum, medulla oblongata and olfactory bulbs. Both retinae were removed and all nervous tissue was stored in liquid nitrogen until the time of assay. Regions were separately homogenised in 10 vol. perchloric acid $0.48 \mathrm{M}$ and the amino acids GABA, glycine, glutamine, aspartic acid, glutamic acid and taurine assayed by the dansyl micro-assay technique as described by Joseph and Halliday (1975). Radiolabelled ${ }^{14} \mathrm{C}$-glycine, glutamine. aspartic acid, glutamic acid, taurine and ${ }^{3} \mathrm{H}$-dansyl chloride were purchased from New England Nuclear, ${ }^{14} \mathrm{C}-\mathrm{GABA}$ from Amersham-Searle and 3-acetyl pyridine from Aldrich Chemical Co. Micropolyamide t.l.c. plates were purchased from Schleicher and Schuell. All solvents were reagent grade and doubledistilled deionised water was used throughout.

\section{RESULTS}

As early as $7-8$ hours after injection of 3-acetyl pyridine, rats showed signs of loss of balance and ataxia. In addition, many had respiratory difficulties. Muscle power, however, did not appear to be affected. The effect of 3-acetyl pyridine administration on brain and retinal amino acids is shown in Tables 1 and 2 .

Glutamic acid levels were found to be significantly decreased in many brain regions; medulla oblongata, cerebellum, cerebral cortex, striatum, hippocampus and olfactory bulbs. On the other hand, the amino acid taurine was depleted only in medulla oblongata and cerebellum (Table 1). No change in GABA, glycine or aspartic acid were found in any of the brain regions studied, following 3-acetyl pyridine treatment.

Table 2 demonstrates a highly significant $(p<0.001)$ decrease in reti- 
TABLE 1

Effect of 3-acetyl pyridine (75 $\mathrm{mg}$ per $\mathrm{kg}$ ) on brain amino acids.

\begin{tabular}{|c|c|c|c|c|c|c|c|c|}
\hline \multirow[t]{2}{*}{ BRAIN REGION } & \multirow[t]{2}{*}{ TREATMENT } & \multirow[t]{2}{*}{$\underline{\mathbf{N}}$} & \multicolumn{6}{|c|}{ AMINO ACID CONCENIRATION $\mu$ mole $g^{-1}$ (I S.E.M.) } \\
\hline & & & $\underline{\text { GABA }}$ & GLYCINE & GUTAMME & ASPARIIC ACID & GUIAMIC ACID & TAURINE \\
\hline \multirow[t]{2}{*}{ CERERELLUM } & 3-acetyl pyridine & 11 & $1.47 \pm 0.06$ & $0.75 \pm 0.03$ & $\star * 7.03 \pm 0.37$ & $2.75 \pm 0.21$ & $\star 9.42 \pm 0.17$ & $* 4.37 \pm 0.23$ \\
\hline & Saline & 12 & $1.58 \pm 0.04$ & $0.74 \pm 0.03$ & $5.79 \pm 0.20$ & $2.85 \pm 0.23$ & $10.17 \pm 0.21$ & $5.23 \pm 0.23$ \\
\hline \multirow{2}{*}{$\begin{array}{l}\text { MEDOILA } \\
\text { OBLONCATA }\end{array}$} & 3-acetyl pyridine & 12 & $1.57 \pm 0.05$ & $3.64 \pm 0.18$ & $\star \star 4.01 \pm 0.22$ & $3.03 \pm 0.22$ & $\bullet 5.57 \pm 0.14$ & $\star \star \star 1.09 \pm 0.08$ \\
\hline & Saline & 12 & $1.76 \pm 0.06$ & $3.55 \pm 0.14$ & $3.20 \pm 0.07$ & $3.21 \pm 0.22$ & $6.02 \pm 0.15$ & $1.79 \pm 0.16$ \\
\hline \multirow[t]{2}{*}{ CORTEX } & 3-acetyl pyridine & 12 & $1.89 \pm 0.08$ & $0.79 \pm 0.08$ & $* * * 7.14 \pm 0.48$ & $4.07 \pm 0.44$ & $* * 10.93 \pm 0.19$ & $6.00 \pm 0.31$ \\
\hline & Saline & 12 & $1.97 \pm 0.12$ & $0.56 \pm 0.08$ & $5.28 \pm 0.12$ & $4.04 \pm 0.38$ & $11.88 \pm 0.26$ & $6.48 \pm 0.30$ \\
\hline \multirow[t]{2}{*}{ MIDBRAIN } & 3-acetyl pyridine & 12 & $3.14 \pm 0.16$ & $1.80 \pm 0.08$ & $\star \star 4.76 \pm 0.33$ & $2.78 \pm 0.15$ & $6.76 \pm 0.24$ & $1.30 \pm 0.11$ \\
\hline & Saline & 11 & $2.96 \pm 0.06$ & $1.62 \pm 0.07$ & $3.94 \pm 0.16$ & $2.84 \pm 0.19$ & $7.15 \pm 0.27$ & $1.49 \pm 0.11$ \\
\hline \multirow[t]{2}{*}{ STRIATUM } & 3-acetyl pyridine & 12 & $2.78 \pm 0.18$ & $1.1 .2 \pm 0.07$ & $4.91 \pm 0.26$ & $1.92 \pm 0.19$ & $* 6.75 \pm 0.31$ & $7.95 \pm 0.70$ \\
\hline & Saline & 12 & $2.81 \pm 0.13$ & $0.99 \pm 0.07$ & $4.84 \pm 0.28$ & $1.89 \pm 0.15$ & $8.27 \pm 0.42$ & $8.48 \pm 0.37$ \\
\hline \multirow[t]{2}{*}{ HIPPOCAMPUS } & 3-acetyl pyridine & 12 & $2.50 \pm 0.10$ & $1.08 \pm 0.06$ & $5.59 \pm 0.24$ & $3.01 \pm 0.16$ & $\star 9.71 \pm 0.28$ & $5.37 \pm 0.25$ \\
\hline & Saline & 12 & $2.53 \pm 0.09$ & $0.82 \pm 0.06$ & $4.91 \pm 0.12$ & $2.89 \pm 0.21$ & $10.89 \pm 0.37$ & $5.58 \pm 0.43$ \\
\hline \multirow[t]{2}{*}{ OLFACTORY BUTBS } & 3-acetyl pyridine & 12 & $3.74 \pm 0.10$ & $0.84 \pm 0.06$ & $\star 6.25 \pm 0.35$ & $2.28 \pm 0.15$ & $\star 6.65 \pm 0.28$ & $10.09 \pm 0.59$ \\
\hline & Saline & 12 & $3.88 \pm 0.15$ & $0.72 \pm 0.05$ & $5.34 \pm 0.21$ & $2.54 \pm 0.19$ & $7.67 \pm 0.30$ & $11.34 \pm 0.49$ \\
\hline \multirow[t]{2}{*}{ HYPOTHAIAMLS } & 3-acetyl pyridine & 12 & $5.03 \pm 0.23$ & $1.10 \pm 0.07$ & $\star 6.16 \pm 0.23$ & $2.75 \pm 0.13$ & $6.85 \pm 0.23$ & $1.92 \pm 0.16$ \\
\hline & saline & 12 & $5.55 \pm 0.23$ & $1.17 \pm 0.08$ & $5.52 \pm 0.11$ & $3.13 \pm 0.17$ & $7.84 \pm 0.46$ & $1.95 \pm 0.12$ \\
\hline & & & & $\begin{array}{r}\star \\
\star \star \\
\star * \star\end{array}$ & $\begin{array}{l}<0.05 \\
<0.01 \\
<0.001\end{array}$ & & & \\
\hline
\end{tabular}

TABLE 2

Effect of 3-acetyl pyridine ( $75 \mathrm{mg}$ per $\mathrm{kg}$ ) on retinal amino acids.

TREATMENT
3-acetyl pyridine $12 \quad 1.95 \pm 0.13$
Saline
nal $12 \quad 1.94 \pm 0.11$
less severe but statistically signific-
ant (p<0.05) depletion of glutamic
acid. In the case of retina, no
changes were observed in the levels
of GABA, glycine, glutamine and
taurine following 3-acetyl pyridine
treatment.

\section{DISCUSSION}

Microscopic examination of the central nervous system of 3-acetyl pyridine treated rats reveals highly reproducible grey matter lesions de- tectable as early as 7 hours after a single injection (Desclin and Escubi, 1974). Total destruction of the inferior olivary complex and an almost complete destruction of the nucleus ambiguus is observed and fiber tracts originating in these structures contain degenerating fibers. The degenerating fibers originating in the inferior olives were found to follow olivocerebellar tracts. Cerebellar climbing fibers were selectively destroyed. In addition, smaller discrete lesions were detected in the substan- tia nigra, the nucleus of the basal optic root and the nucleus dorsalis of the raphe in the midbrain.

The existence of multiple lesions in the medulla was confirmed biochemically (Table 1); both taurine and glutamic acid levels being severely depleted in the medulla oblongata of rats receiving 3-acetyl pyridine when compared to saline-treated controls. This result contrasts with that of Nadi et al. (1977), who found increased aspartic and glutamic acids. In the latter 
case, however, amino acids were measured 21 days after injection of 3-acetyl pyridine.

In the cerebellum, only climbing fibers appear to be affected by 3-acetyl pyridine injections. Degeneration of these fibers is very rapid, and clearing of degenerated tissue has been found to be complete $72 \mathrm{hrs}$ after treatment (Desclin and Escubi, 1974). Both taurine and glutamic acid were found by us to be decreased in cerebellum. This observation is of particular interest as there is evidence that both amino acids may function as neurotransmitters in that part of the brain. The amino acid glutamine was found to be increased. A decreased concentration of taurine accompanied by increased glutamine levels in the cerebellum of rats treated with 3-acetyl pyridine is in agreement with the findings of Perry et al. (1976), who studied the compounds' effects on the levels of the ten most abundant amino acids in rat cerebellum. These workers, however, found only slight decreases in cerebellar glutamate in contrast to the rather marked decreased found by us (Table 1). This difference may possibly be due to the fact that our animals were sacrificed 3 days following 3 -acetyl pyridine whereas those of Perry et al. (1976) were sacrificed at various times ranging from 3 days to 3 weeks. The finding of decreased glutamic acid in the cerebellum of 3 -acetyl pyridine treated animals is of particular interest in view of the observation that the climbing fibers, substantially destroyed by 3-acetyl pyridine, constitute an excitatory input into cerebellum. Our results offer evidence that glutamic acid may be the excitatory neurotransmitter of the climbing fibers. This observation supports the contention by Guidotti et al. (1975), a contention based on glutamate's ability when administered intraventricu- larly, to cause an increase in cerebellar cGMP in both control and 3-acetyl pyridine treated rats.

Diminished taurine levels found in both cerebellum and medulla may be explainable by failure of taurine synthesis at the level of cysteine oxidation, as has been proposed by Perry et al. (1976). It has also been suggested that the toxic effects of 3-acetyl pyridine may be due to the competition of 3-acetyl pyridine with nicotinamide for incorporation into NAD. Administration of nicotinamide has been shown to prevent the lethal effects of 3-acetyl pyridine (Simontov et al, 1976). In vitro experiments have shown that 3-acetyl pyridine-NAD is only one tenth as effective as NAD as a cofactor for cysteine oxidase (Misra and Olney, 1975).

Amino acid changes found by us in retina, namely substantial decreases in both glutamic and aspartic acids, are more difficult to explain. A fuller understanding of these changes awaits histological studies on retinae of rats treated with 3-acetyl pyridine.

In conclusion, ataxia produced by 3-acetyl pyridine is accompanied by changes in the concentrations of certain amino acids alleged to have neurotransmitter function. These changes are most pronounced in brain regions known to be selectively affected by 3 -acetyl pyridine. This selective vulnerability of certain neurons to chemical changes may be of key importance in the understanding of degenerative diseases involving selective brain areas or fiber tracts. Whether the changes in concentration of the amino acids observed in the present study will be found to have similarities to those in the brains of patients suffering from olivo cerebellar atrophy (OCA) awaits further study. In the meantime, it is of interest that a recent report finds changes in taurine and aspartic acid in autopsied brain from two members of a family suffering from a dominantly inherited form of olivo ponto cerebellar atrophy (Perry et al., 1977), a disease with a clinical symptomatology and course similar to that of OCA.

\section{ACKNOWLEDGMENTS}

These studies were carried out under grants from La Fondation Jeanne Mance (HôtelDieu de Montréal), l'Association Canadienne de l'Ataxie de Friedreich and the Medical Research Council of Canada.

\section{REFERENCES}

DESCLIN, J. C. and ESCUBI, J. (1974). Effects of 3-acetyl pyridine on the central nervous system of the rat, as demonstrated by silver methods. Brain Res., 77, 349-363.

GUIDOTTI, A., BIGGIO, G. and COSTA, E. (1975). 3-Acetyl pyridine: a tool to inhibit the tremor and the increase of cGMP content in cerebellar cortex elicited by harmaline. Brain Res., 96, 201-205.

HOLMES, G. (1907). A form of familial degeneration of cerebellum. Brain, 30 , 466.471.

JOSEPH, M. H. and HALLIDAY, J. (1975). A dansylation microassay for some amino acids in brain. Anal. Biochem., 64, 389-402.

MISRA, C. H. and OLNEY, J. W. (1975). Cysteine oxidase in brain. Brain Res., 97, 117-126.

NADI, N. S., KANTER, D., McBRIDE, W. J. and APRISON, M. H. (1977). Effects of 3-acetyl pyridine on several putative neurotransmitter amino acids in the cerebellum and medulla of the rat. J. Neurochem., 28, 661-662.

PERRY, T. L. CURRIER, R. D., HANSEN, S. and MacLEAN, J. (1977). Aspartate-taurine imbalance in dominantly inherited olivopontocerebellar atrophy. Neurology, 27, 257-261.

PERRY, T. L., MacLEAN, J., PERRY, Jr., T. L. and HANSEN, S. (1976). Effects of 3-acetyl pyridine on putative neurotransmitter amino acids in rat cerebellum. Brain Res., 109, 632-635.

SIMONTOV, R., SNYDER, S. H. and OSTER-GRANITE, M. L. (1976). Harmaline-induced tremor in the rat; abolition by 3-acetyl pyridine destruction of cerebellar climbing fibers. Brain Res., 114, 144-15I. 